\title{
EVALUASI SISTEM INFORMASI UNTUK MENGETAHUI TINGKAT KEPUASAN PENGGUNA WWW.MY.UNPAM.AC.ID DENGAN MENGGUNAKAN METODE EUCS DAN PIECES
}

\author{
Heri Haerudin \\ Fakultas Teknik, Universitas Pamulang \\ e-mail: heri2709@gmail.com
}

\begin{abstract}
ABSTRAK
Universitas Pamulang merupakan salah satu universitas swasta terbesar di wilayah Kota Tangerang Selatan yang mempunyai lebih dari 30.000 orang mahasiswa. Untuk itu sangat diperlukan sistem informasi akademik yang berkualitas agar dapat memenuhi kepuasan pengguna dan dapat memperbesar niat para pengguna untuk menggunakannya. Untuk saat ini di Universitas Pamulang sudah terdapat sistem informasi yang berbasis web yang menyediakan informasi tentang hasil studi mahasiswa, dan pembayaran kuliah. Tujuan dari penelitian ini adalah untuk mengukur kualitas dari sistem informasi akademik khususnya my.unpam.ac.id dan mencari tahu seberapa besar tingkat kepuasan pengguna. Ada dua model evaluasi yang digunakan dalam penelitian ini, yang pertama adalah EUCS, model kedua yang digunakan adalah model PIECES. Secara keseluruhan hasil review terhadap www.my.unpam.ac.id menunjukan adanya tingkat kepuasan dan ketidakpuasan pengguna terhadap www.my.unpam.ac.id dari dimensi EUCS dan PIECES. Dari segi tampilan dan cara penyajian laporan, rata-rata responden sudah puas. Namun dari segi keakuratan data dan update yang dihasilkan, rata-rata responden masih kurang puas.
\end{abstract}

Kata kunci : Sistem Informasi, Kepuasan Pengguna, EUCS, PIECES.

\section{PENDAHULUAN}

Sistem Informasi (SI) dapat didefinisikan sebagai serangkaian prosedur formal di mana data dikumpulkan, diproses menjadi informasi, dan didistribusikan kepada para pemakai [1]. Selama dekade terakhir, sistem informasi telah mengubah organisasi-organisasi ekonomi secara fundamental dan sangat banyak meningkatkan kemungkinan untuk mengatur pekerjaan [2]. Universitas Pamulang merupakan salah satu universitas swasta terbesar di wilayah Kota Tangerang Selatan yang mempunyai lebih dari 30.000 orang mahasiswa (Data tahun 2014). Untuk itu sangat diperlukan sistem informasi akademik yang berkualitas agar dapat memenuhi kepuasan pengguna untuk memperbesar niat para pengguna untuk menggunakannya.

Permasalahan yang menjadi dasar untuk melakukan penelitian ini, yaitu : (a) Masih terdapat bug dan error pada sistem informasi nilai mata kuliah di www.my.unpam.ac.id; (b) Belum pernah diadakannya evaluasi terhadap www.my.unpam.ac.id.

Berdasarkan latar belakang masalah diatas, maka rumusan masalah dalam penelitian ini adalah Bagaimana pengukuran kepuasan pengguna dengan model EUCS dan PIECES untuk mengevaluasi www.my.unpam.ac.id Universitas pamulang?

Tujuan dari penelitian ini adalah untuk mengukur kualitas dari sistem informasi akademik, khususnya my.unpam.ac.id dan mencari tahu seberapa besar tingkat kepuasan pengguna my.unpam.ac.id dengan menggunakan metode EUCS dan PIECES.

Manfaat yang dapat diambil dari hasil penelitaian ini adalah mendapatkan suatu gambaran tentang pendapat dan keinginan pengguna akhir terhadap www.my.unpam.ac.id dan mendapatkan masukan untuk pengembangan sistem berikutnya.

\section{End User Computing Satisfaction (EUCS)}

End User Computing Satisfaction (EUCS) adalah metode untuk mengukur tingkat kepuasan dari pengguna suatu sistem aplikasi dengan membandingkan antara harapan dan kenyataan dari sebuah sistem informasi. Definisi End User Computing Satisfaction dari sebuah sistem informasi adalah evaluasi secara keseluruhan dari para pengguna sistem informasi yang berdasarkan pengalaman mereka dalam menggunakan sistem tersebut[10]. Evaluasi dengan menggunakan model ini lebih menekankan kepuasan (satisfaction) pengguna 
akhir terhadap aspek teknologi, dengan menilai isi, keakuratan, format, waktu dan kemudahan penggunaan dari sistem.

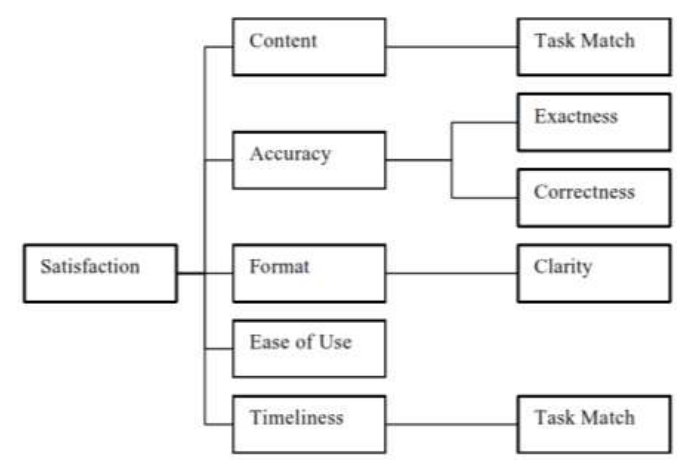

Gambar 1. Model Evaluasi End User Computing Satisfaction

\section{Performance Information Economics Efficiency Service (PIECES)}

Ada banyak permasalahan, kesempatan dan arah pengembangan dalam suatu sistem informasi, karena itu James Wetherbe mengembangkan suatu kerangka kerja yang berguna untuk mengklasifikasikannya yang disebut PIECES (Performance Information Economics Control Efficiency Service)[11]. Kerangka kerja PIECES sebagai berikut:

a. Performance

1. Produksi

2. Waktu respon

b. Information

1. output

2. input

3. penyimpanan data

c. Economics

1. Biaya

2. Keuntungan

d. Control

1. Keamanan/control terlalu lemah

2. Keamanan/control berlebihan

e. Efficiency

1. Orang, mesin, atau komputer membuang waktu

2. Orang, mesin, atau komputer membuang material dan persediaan

3. Usaha yang dibutuhkan untuk tugastugas terlalu berlebihan

4. Material yang dibutuhkan untuk tugas-tugas terlalu berlebihan

f. Services

1. Sistem menghasilkan produk yang tidak akurat
2. Sistem menghasilkan produk yang tidak konsisten

3. Sistem menghasilkan produk yang tidak dapat dipercaya

4. Sistem tidak mudah dipelajari

5. Sistem tidak mudah digunakan

6. Sistem canggung untuk digunakan

7. Sistem tidak fleksibel pada situasi baru atau tidak umum

8. Sistem tidak fleksibel untuk berubah

9. Sistem tidak kompatibel dengan sistem-sistem lain

\section{METODE PENELITIAN}

Pada portal www.my.unpam.ac.id mahasiswa bisa mengakses atau mendapatkan informasi tentang nilai, KRS, pembayaran, jadwal mata kuliah dan pengumuman terbaru tentang kegiatan perkuliahan.

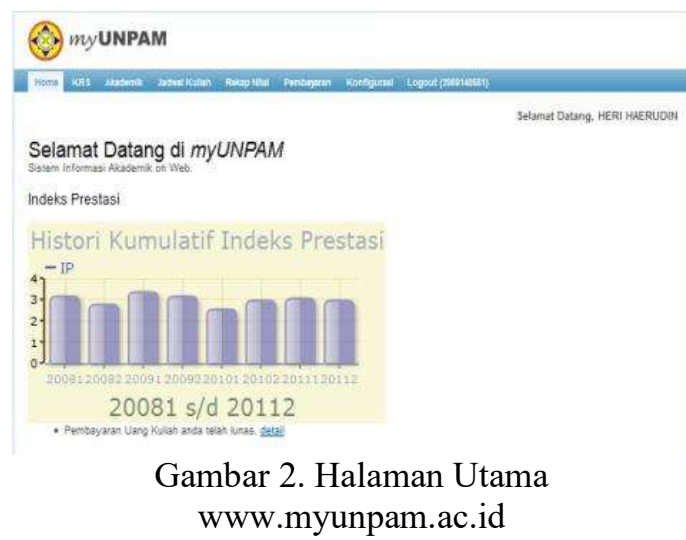

Pengumpulan data dalam penelitian ini menggunakan penelitian lapangan. Penelitian lapangan dilakukan dengan menggunakan kuesioner.

\section{Metode Pemilihan Sampel}

a. Populasi

Dalam penelitian ini yang menjadi subjek penelitian adalah mahasiswa aktif Universitas Pamulang yang terdiri:

Tabel 1. Jumlah populasi mahasiswa Universitas Pamulang

\begin{tabular}{|c|l|l|}
\hline No & \multicolumn{1}{|c|}{ Program Studi } & $\begin{array}{c}\text { Jumlah } \\
\text { Mahasiswa }\end{array}$ \\
\hline 1 & Teknik Elektro & 1127 \\
\hline 2 & Teknik Mesin & 1478 \\
\hline 3 & Teknik Kimia & 153 \\
\hline 4 & Teknik Industri & 1078 \\
\hline 5 & Matematika & 324 \\
\hline 6 & Teknik Informatika & 6512 \\
\hline
\end{tabular}


ISSN 2541-1004

\begin{tabular}{|c|l|l|}
\hline 7 & Magister Manajemen & 259 \\
\hline 8 & Manajemen & 9550 \\
\hline 9 & Akuntansi S1 & 6098 \\
\hline 10 & Akuntansi D3 & 348 \\
\hline 11 & Sekretaris & 210 \\
\hline 12 & Magister Hukum & 90 \\
\hline 13 & Ilmu Hukum & 2208 \\
\hline 14 & Sastra Indonesia & 295 \\
\hline 15 & Sastra Inggris & 1757 \\
\hline 16 & Pendidikan Ekonomi & 152 \\
\hline 17 & $\begin{array}{l}\text { Pendidikan Pancasila } \\
\text { Dan } \\
\text { Kewarganegaraan }\end{array}$ & 844 \\
\hline \multicolumn{2}{|c|}{ Jumlah Total } & 32483 \\
\hline
\end{tabular}

b. Sample

Teknik sampling yang digunakan untuk penelitian ini adalah Cluster Sampling.

Rumus Slovin:

$\mathrm{N}=$ Populasi 32483 mahasiswa

$\mathrm{d}=$ nilai presisi $90 \%$ atau sig. $=0,1$.

Maka :

$$
\begin{gathered}
\mathrm{n}=\frac{\mathrm{N}}{1+\left(\mathrm{N} * \mathrm{~d}^{2}\right)} \\
\mathrm{n}=\frac{32.483}{1+\left(32.483 *(0,1)^{2}\right)} \\
\mathrm{n}=\frac{32.483}{1+(32.483 * 0.01)} \\
\mathrm{n}=\frac{32483}{1+324,83} \\
\mathrm{n}=99,69
\end{gathered}
$$

Jadi jumlah sampel untuk seluruh program studi adalah 100.

Tabel 2. Pengambilan Sampel Berdasarkan Program Studi

\begin{tabular}{|l|l|l|l|}
\hline No & Program Studi & $\begin{array}{l}\text { Jumlah } \\
\text { Mahasiswa }\end{array}$ & Sampel \\
\hline 1 & Teknik Elektro & 1127 & 3 \\
\hline 2 & Teknik Mesin & 1478 & 5 \\
\hline 3 & Teknik Kimia & 153 & 1 \\
\hline 4 & Teknik Industri & 1078 & 3 \\
\hline 5 & Matematika & 324 & 1 \\
\hline 6 & $\begin{array}{l}\text { Teknik } \\
\text { Informatika }\end{array}$ & 6512 & 20 \\
\hline 7 & $\begin{array}{l}\text { Magister } \\
\text { Manajemen }\end{array}$ & 259 & 1 \\
\hline 8 & Manajemen & 9550 & 29 \\
\hline 9 & Akuntansi S1 & 6098 & 19 \\
\hline 10 & Akuntansi D3 & 348 & 1 \\
\hline
\end{tabular}

\begin{tabular}{|l|l|l|l|}
\hline 11 & Sekretaris & 210 & 1 \\
\hline 12 & Magister Hukum & 90 & 0 \\
\hline 13 & Ilmu Hukum & 2208 & 7 \\
\hline 14 & Sastra Indonesia & 295 & 1 \\
\hline 15 & Sastra Inggris & 1757 & 5 \\
\hline 16 & $\begin{array}{l}\text { Pendidikan } \\
\text { Ekonomi }\end{array}$ & 152 & 0 \\
\hline 17 & $\begin{array}{l}\text { Pendidikan } \\
\text { Pancasila Dan } \\
\text { Kewarganegaraan }\end{array}$ & 844 & 3 \\
\hline \multicolumn{2}{|l|}{ Jumlah Sampel } & 100 \\
\hline
\end{tabular}

\section{Variabel Penelitian}

Variable kriteria dalam End Using Computing Satisfactions (EUCS) :

1. Content ; 2. Accuracy; 3. Format; 4. Easy Of Use; 5. Timelines; 6. Satisfaction with System Speed; 7. System Reliability

Variable kriteria dalam Performance, Information, Economy, Control, Efficiency And Services (PIECES) :

1. Performance (Performa sistem)

2. Informations (Penyajian informasi sistem)

3. Economics (Nilai ekonomis sistem)

4. Control (Tingkat pengendalian dan pengamanan)

5. Efficiency (Tingkat keefisienan dan keefektifan)

\section{Skala Variabel Penelitian}

Skala pengukuran variabel dalam penelitian ini mengacu pada Skala Likert (Likert Scale), dimana masing-masing dibuat dengan menggunakan skala $1-5$ kategori jawaban, yang masing-masing jawaban diberi score atau bobot yaitu banyaknya score antara 1 sampai 5 , dengan rincian: a. Jawaban SS sangat setuju diberi score 5; b. Jawaban S setuju diberi score 4; c. Jawaban $\mathrm{R}$ ragu-ragu diberi score 3; d. Jawaban KS kurang setuju diberi score 2; e. Jawaban TS tidak setuju diberi score 1.

\section{Teknik Analisis Data}

Teknik analisis data yang digunakan dalam penelitian ini adalah teknik analisisi deskriptif kuantitatif. Penyajian data yang dilakukan dengan mencari frekuensi mutlak, frekuensi relatif (mencari persentase), serta mencari ukuran tendensi sentralnya yaitu: mode, median dan mean.

\section{PEMBAHASAN}

\section{Hasil Sebaran Kuisioner}

Kuesioner disebarkan secara langsung kepada responden yang terdiri dari 17 fakultas 
ISSN 2541-1004

yang ada di Universitas Pamulang dengan jumlah responden terdaftar sebanyak 100, jumlah pertanyaan sebanyak 23 pertanyan.

Tabel 3. Rekap hasil pengisian Kuisioner Dimensi EUCS dan PIECES

\begin{tabular}{|c|c|c|c|c|c|}
\hline $\begin{array}{c}\text { Nomor } \\
\text { Pernyataan }\end{array}$ & SS & S & $\mathbf{R}$ & KS & TS \\
\hline 1 & 15 & 73 & 10 & 2 & 0 \\
\hline 2 & 0 & 15 & 74 & 9 & 2 \\
\hline 3 & 2 & 20 & 52 & 20 & 6 \\
\hline 4 & 4 & 22 & 43 & 27 & 4 \\
\hline 5 & 3 & 13 & 73 & 9 & 2 \\
\hline 6 & 3 & 23 & 62 & 11 & 1 \\
\hline 7 & 3 & 32 & 53 & 11 & 1 \\
\hline 8 & 10 & 69 & 18 & 1 & 2 \\
\hline 9 & 11 & 78 & 9 & 1 & 1 \\
\hline 10 & 9 & 54 & 30 & 6 & 1 \\
\hline 11 & 5 & 77 & 13 & 5 & 0 \\
\hline 12 & 14 & 70 & 14 & 1 & 1 \\
\hline 13 & 10 & 77 & 9 & 2 & 2 \\
\hline 14 & 2 & 6 & 64 & 21 & 7 \\
\hline 15 & 0 & 0 & 44 & 42 & 14 \\
\hline 16 & 0 & 68 & 27 & 3 & 2 \\
\hline 17 & 0 & 0 & 44 & 42 & 14 \\
\hline 18 & 6 & 82 & 8 & 3 & 1 \\
\hline 19 & 4 & 51 & 28 & 13 & 4 \\
\hline 20 & 6 & 40 & 43 & 10 & 1 \\
\hline 21 & 3 & 23 & 62 & 11 & 1 \\
\hline 22 & 2 & 20 & 52 & 20 & 6 \\
\hline 23 & 9 & 75 & 16 & 0 & 0 \\
\hline 24 & 2 & 20 & 52 & 20 & 6 \\
\hline 25 & 2 & 20 & 52 & 20 & 6 \\
\hline 26 & 2 & 20 & 52 & 20 & 6 \\
\hline 27 & 1 & 80 & 17 & 2 & 0 \\
\hline 28 & 2 & 79 & 17 & 1 & 1 \\
\hline & & & & \\
\hline
\end{tabular}

\section{Hasil Uji Kuisioner}

Karena pengambilan sampel dilakukan sebanyak 100 buah, maka $r$ tabel yang digunakan sebesar 0.165 sesuai dengan taraf signifikan $10 \%$ atau 0,1 .

Tabel 4. Hasil Uji Validitas

\begin{tabular}{|c|l|l|l|}
\hline $\begin{array}{l}\text { Nomor } \\
\text { Pernyataan }\end{array}$ & $\begin{array}{l}\text { Nilai } \\
\mathbf{r}\end{array}$ & $\begin{array}{l}\mathbf{r} \text { Tabel } \\
\mathbf{0 , 1 6 5}\end{array}$ & Keterangan \\
\hline 1 & 0.27 & Lebih Besar & Valid \\
\hline 2 & 0.247 & Lebih Besar & Valid \\
\hline 3 & 0.031 & Lebih Kecil & Tidak Valid \\
\hline 4 & 0 & Lebih Kecil & Tidak Valid \\
\hline 5 & 0.269 & Lebih Besar & Valid \\
\hline 6 & 0.198 & Lebih Besar & Valid \\
\hline
\end{tabular}

\begin{tabular}{|l|l|l|l|}
\hline 7 & 0.234 & Lebih Besar & Valid \\
\hline 8 & 0.214 & Lebih Besar & Valid \\
\hline 9 & 0.408 & Lebih Besar & Valid \\
\hline 10 & 0.361 & Lebih Besar & Valid \\
\hline 11 & 0.205 & Lebih Besar & Valid \\
\hline 12 & 0.414 & Lebih Besar & Valid \\
\hline 13 & 0.517 & Lebih Besar & Valid \\
\hline 14 & 0.201 & Lebih Besar & Valid \\
\hline 15 & 0.243 & Lebih Besar & Valid \\
\hline 16 & 0.235 & Lebih Besar & Valid \\
\hline 17 & 0.243 & Lebih Besar & Valid \\
\hline 18 & 0.286 & Lebih Besar & Valid \\
\hline 19 & 0.402 & Lebih Besar & Valid \\
\hline 20 & 0.168 & Lebih Besar & Valid \\
\hline 21 & 0.252 & Lebih Besar & Valid \\
\hline 22 & 0.524 & Lebih Besar & Valid \\
\hline 23 & 1 & Lebih Besar & Valid \\
\hline
\end{tabular}

Kriteria dari nilai Croanbach's Alpha adalah apabila didapatkan nilai Croanbach's Alpha kurang dari 0,600 berarti buruk, sekitar 0,700 diterima dan lebih dari atau sama dengan 0,800 adalah baik. Nilai Croanbach's Alpha dengan perhitungan SPSS didapat :

$$
\mathrm{r}_{\mathrm{i}}=0,882>0,800
$$

Dari hasil tersebut diketahui bahwa instrumen penelitian memiliki tingkat reliabilitas yang baik.

\section{Implikasi Penelitian}

Dari hasil pengolahan data terhadap kuesioner ada beberapa dimensi yang perlu diperbaiki berkaitan dengan kepuasan pelanggan terhadap www.my.unpam.ac.id berdasarkan model EUCS dan PIECES.

Tabel 5. Hasil Evaluasi Dimensi EUCS

\begin{tabular}{|l|l|l|l|}
\hline $\begin{array}{l}\text { Dimensi } \\
\text { EUCS }\end{array}$ & Pertanyaan & Keterangan & $\begin{array}{l}\text { Rata- } \\
\text { rata }\end{array}$ \\
\hline \multirow{3}{*}{ Isi } & 1 & Valid & 4,01 \\
\cline { 2 - 4 } & 2 & Valid & 3,02 \\
\cline { 2 - 4 } & 3 & Tidak Valid & 2,92 \\
\hline \multirow{4}{*}{ Ketepatan } & 4 & Tidak Valid & 2,95 \\
\cline { 2 - 4 } & 5 & Valid & 3,06 \\
\cline { 2 - 4 } & 6 & Valid & 3,16 \\
\cline { 2 - 4 } & 7 & Valid & 3,25 \\
\hline \multirow{3}{*}{ Format } & 8 & Valid & 3,84 \\
\cline { 2 - 4 } & 9 & Valid & 3,97 \\
\cline { 2 - 4 } Kemudahan \\
Pengguna & 10 & Valid & 3,82 \\
\cline { 2 - 4 } & 11 & Valid & 3,95 \\
\cline { 2 - 4 } & 13 & Valid & 3,91 \\
\hline Aktualitas & 14 & Valid & 2,75 \\
\hline
\end{tabular}




\begin{tabular}{|l|l|l|l|}
\hline & 15 & Valid & 3,61 \\
\cline { 2 - 4 } & 16 & Valid & 2,3 \\
\hline $\begin{array}{l}\text { Kecepatan } \\
\text { Sistem }\end{array}$ & 17 & Valid & 2,3 \\
\hline Kehandalan & 18 & Valid & 3,89 \\
\hline
\end{tabular}

Tabel 6. Hasil Evaluasi Dimensi PIECES

\begin{tabular}{|l|l|l|l|}
\hline $\begin{array}{l}\text { Dimensi } \\
\text { PIECES }\end{array}$ & Pertanyaan & Keterangan & $\begin{array}{l}\text { Rata- } \\
\text { rata }\end{array}$ \\
\hline \multirow{2}{*}{ Performance } & 1 & Valid & 3,38 \\
\cline { 2 - 4 } & 2 & Valid & 3,34 \\
\hline \multirow{2}{*}{ Information } & 3 & Valid & 3,16 \\
\cline { 2 - 4 } & 4 & Valid & 3,02 \\
\hline Economy & 5 & Valid & 3,93 \\
\hline Control & 6 & valid & 3,8 \\
\hline \multirow{2}{*}{ Efficiency } & 7 & Valid & 3,8 \\
\cline { 2 - 4 } & 8 & Valid & 3,8 \\
\hline Service & 9 & Valid & 3,8 \\
\hline
\end{tabular}

\section{KESIMPULAN}

Dari hasil pengolahan data yang telah dilakukan, diperoleh kesimpulan dari masingmasing dimensi kepuasan, pada model EUCS (End Using Computing Satisfactions). Perolehan rata-rata dimensi Content sebesar 3,31; Accuracy sebesar 3,11; Format sebesar 3,87; Ease of use pengguna sebesar 3,54; Timelines pengguna sebesar 2,73; Satisfaction With System Speed sebesar 2,3; dan System Reliability sebesar 3,89; Sedangkan Model PIECES (Performance, Information, Economy, Control, Eficiency and Service). Perolehan rata-rata dimensi Performance sebesar 3,36; Information sebesar 3,09; Economy sebesar 3,89; Control sebesar 3,8; Efficiency sebesar 3,8; dan Services sebesar 3,8;

Secara keseluruhan hasil review terhadap www.my.unpam.ac.id menunjukan adanya tingkat puas dan kurang puasnya pengguna terhadap www.my.unpam.ac.id dari dimensi EUCS dan PIECES. Dari segi tampilan dan cara penyajian laporan rata-rata responden sudah puas. Namun dari segi keakuratan data dan update yang dihasilkan rata-rata responden masih kurang puas.

\section{DAFTAR PUSTAKA}

[1] Hall, J. A. (2012). Accounting Information System. Newyork: McGrawHill Companies Inc.

[2] Kenneth C. Laudon, Jane P. Laudon, (2007). Management Informations Systems Managing The Digital Firm 10th Editions.

[3] Jogiyanto, H.M., (2005). Analisa dan Desain Sistem Informasi: Pendekatan Terstruktur Teori dan Praktik Aplikasi Bisnis. Yogyakarta: Andi.
[4] O'Brien, James A. (2005). Introduction to Information System, 12th Edition. McGrawHill Companies Inc., New York

[5] Stair, R., Reynolds, G. (2010). Principles of Information Systems. 9th Edition. Course Technology, Cengage Learning, United States of America.

[6] Turban, Efraim. Kelly, R. Rainer. Richard Jr., E. Potter. (2003). Introduction to Information Technology, 2nd Edition. John Wiley and Sons, Inc, New York.

[7] Chin, W.W., \& Lee, M. K. O. (2000). A proposed model and measurement instrument for the formation of issatisfaction: The case of end-user computing satisfaction. Proceedings of The TwentyFirst International Conference OnInformation Systems. 175-186.

[8] Arikunto, Suharsimi. (2006). Prosedur Penelitian (Suatu Pendekatan Praktek), Jakarta : Rhineka Cipta.

[9] Gordon B. Davis, (1988). Sistem Informasi Manajemen. Pustaka Binaan : Resindo, Jakarta.

[10] Doll, W.J., and G.Torkzadeh. (1988). The Measurement of End-user Computing Satisfaction. MIS Quarterly 12, June.

[11] Whitten, J.L. dan Bentley L. D. 2008. Introduction To System Analysis \& Design. Los Angeles : McGrawHill. 